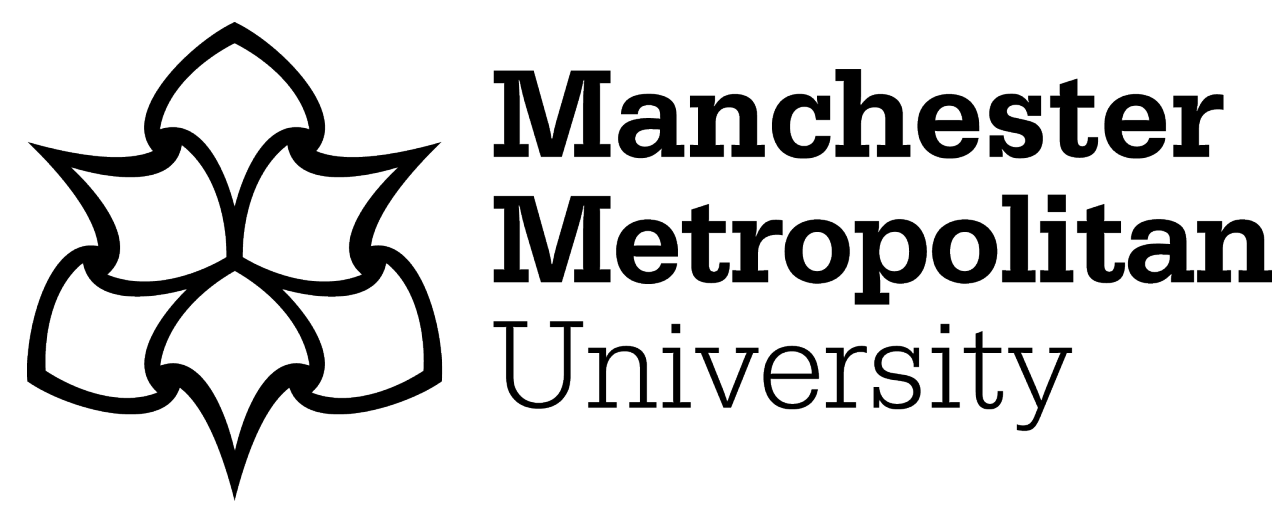

Chang, Y, Wann, DL and Inoue, Y ORCID logoORCID: https://orcid.org/00000002-1983-6217 (2018) The effects of implicit team identification (iTeam ID) on revisit and WOM intentions: A moderated mediation of emotions and flow. Journal of Sport Management, 32 (4). pp. 334-347. ISSN 1543-270X

Downloaded from: https://e-space.mmu.ac.uk/624290/

Version: Accepted Version

Publisher: Human Kinetics

DOI: https://doi.org/10.1123/jsm.2017-0249

Please cite the published version 


\title{
The Effects of Implicit Team Identification on Revisit and Word-of-Mouth Intentions: A Moderated Mediation of Emotions and Flow
}

\author{
Yonghwan Chang*, Daniel L. Wann, \& Yuhei Inoue
}

\section{Author Details:}

*Yonghwan Chang, Ph.D. (Corresponding Author)

Assistant Professor

School of Kinesiology, University of Minnesota

222A Cooke Hall, 1900 University Ave. SE, Minneapolis, MN 55455

Phone: 1.352.682.3097; Email: changy@umn.edu

Daniel L. Wann, Ph.D.

Professor

Department of Psychology, College of Humanities and Fine Arts, Murray State University 201 Wells Hall, Murray, KY 42071

Phone: 1.207.809.2860; Email: dwann@murraystate.edu

Yuhei Inoue, Ph.D.

Assistant Professor

School of Kinesiology, University of Minnesota

218 Cooke Hall, 1900 University Ave. SE, Minneapolis, MN 55455

Phone: 1.612.624.2317; Email: yinoue@umn.edu

\section{Acknowledgments}

The authors appreciate the insightful comments of Chris Janiszewski on an earlier draft of this manuscript. We also would like to acknowledge the invaluable input of Associate Editor Jeffrey James and the anonymous reviewers. Any remaining errors are our own.

Please cite this article as: Chang, Y., Wann, D. L., \& Inoue, Y. (2018). The effects of implicit team identification (iTeam ID) on revisit and WOM intentions: A moderated mediation of emotions and flow. Journal of Sport Management, 32(4), 334-347. 


\title{
The Effects of Implicit Team Identification on Revisit and Word-of-Mouth Intentions: \\ A Moderated Mediation of Emotions and Flow
}

\begin{abstract}
Through this study attempts were made to (1) define the concept of implicit team identification (iTeam ID), (2) examine the effects the interactions between iTeam ID and emotions exert on flow, and (3) examine the behavioral consequences of flow in the context of spectator sports. The opponent process and implicit memory theories served as the study's main theoretical frameworks. An experiment was conducted in which we developed the Team Identification Implicit Association Test (Team ID IAT) as a measure of iTeam ID, and manipulated spectators' emotions based on their retrospective spectating experiences. We conclude from the findings that anger, fear, and sadness paradoxically enhanced flow experiences and subsequent consumption behaviors for spectators with stronger iTeam ID, while happiness was universally appealing regardless of the level of iTeam ID. A recommendation is to strategically create experiences that elicit both positive and negative emotions in spectators to encourage flow.
\end{abstract}

Keywords: implicit team identification, unconscious cognition, emotion, flow, spectator sports 
Given the emergence of positive psychology (Seligman \& Csikszentmihalyi, 2000), scholars have increasingly focused on attempting to determine those experiences and outcomes that make an individual's life worth living. Within Sport Management there has been an increasing emphasis on better understanding how fans' subjective experiences of sport contribute to their well-being, health, and life satisfaction (Doyle, Filo, Lock, Funk, \& McDonald, 2016; Inoue, Berg, \& Chelladurai, 2015). One of the core constructs of the positive psychology movement is the concept of flow (or optimal experiences) as a key state of an individual's experience that contributes to the individual's satisfaction, repeat patronage (Richard \& Chebat, 2016), and quality of life (Asakawa, 2010; Csikszentmihalyi, 1990).

In the context of sport, the phrase 'being in flow' is typically used to describe a state in which an individual feels fully immersed and 'in the zone' in a given ongoing activity without experiencing reflective self-consciousness (Csikszentmihalyi, 1990; Jackson \& Csikszentmihalyi, 1999). Following a similar logic, in the context of spectator sports, when fans reach the state of being in flow in viewing a game, they may experience time distortion, loss of self-consciousness, and detachment from their surroundings. These sensations are a result of a heightened, yet effortless, level of concentration and absorption into the game at hand.

Flow emerges when people are fully engaged, deeply involved, and/or motivated when performing an activity such as sports participation and watching a favorite team's game (Asakawa, 2010; Csikszentmihalyi, 1990; Jackson \& Csikszentmihalyi, 1999). In the context of spectator sports, variations in flow could largely be explained by spectators' identification with a specific team, or team identification (team ID). In other words, those who have a stronger team ID (i.e., individuals perceive themselves as fans of the team, and view the team as a representation of themselves; Branscombe \& Wann, 1992) are more likely to experience the state 
of being in flow when they watch a game featuring their favored team. Moreover, this flow state represents an effortless, automatic, and nonconscious process (Csikszentmihalyi, 1990; Peterson, Park, \& Seligman, 2005). Spectators' unconscious and implicit levels of self-concept representation with a team, namely, implicit team ID (iTeam ID), may largely account for spectators' flow experiences. Supporting this assumption, an increasing number of researchers have suggested the prevalent role of unconscious cognition in predicting behavior (Alter \& Oppenheimer, 2009; Greenwald et al., 2009), especially in the case of identity-based mental processes (Liu, 2016; Tacikowski, Freiburghaus, \& Ehrsson, 2017).

Sport spectatorship, as a form of experiential consumption (Holbrook \& Hirschman, 1982), could be conducive to various emotional responses that may significantly influence how spectators experience flow. The opponent process theory (Solomon \& Corbit, 1974) may account for the interactive effects between iTeam ID and emotions on flow. At the core of this theory is the idea that the more an individual is exposed to the same stimuli over time, the more the initial emotional reaction begins to decrease in intensity, while the opponent process is strengthened. For example, fans may not necessarily be able to maximize their flow experience by watching decisive games (e.g., games in which fans' favorite team continuously score) because exposures to repetitive stimuli are likely to produce tediousness and fatigue (Ein-Gar, Shiv, \& Tormala, 2012). Instead, the experience of watching close, dynamic (Trail \& James, 2001), and uncertain games (Hogan, Massey, \& Massey, 2017) that produce psychological stress (Trail \& James, 2001; Wann, 1995) and create negative emotions (e.g., fear and anxiety) for fans may counterintuitively augment fans' flow experience (Csikszentmihalyi, 1990; Jackson \& Csikszentmihalyi, 1999). This phenomenon is particularly related to spectators with a high iTeam ID, considering their cumulative and repetitive experiences with their favorite team. 
Hence, the seeming paradox of the positive effects of negative emotions on flow may exist in the given context when considering the conjunctional influence of iTeam ID.

Based on this understanding, we attempted to (1) define the concept of iTeam ID, (2) examine the effects that the interactions between iTeam ID and emotions exert on flow, and (3) examine the behavioral consequences of flow in the context of spectator sports. The current study contributes to existing sport consumer behavior and spectatorship literature in the following ways. First, this study attends to a theoretical expansion of the team ID concept by utilizing the account of implicit memory (Gawronski \& Bodenhausen, 2006). The team ID construct has maintained a central position in sport spectatorship research. However, existing team ID concepts predominantly rely on spectators' conscious and deliberate processes (e.g., Lock et al., 2014; Wann \& Branscombe, 1990). The concept of iTeam ID broadens the field's understanding of team ID by elucidating fans' unconscious and implicit levels of identification with teams.

Second, in the past two decades, conceptualizations of the flow experience and its role in an individual's life have undergone extensive advancements. However, existing studies associated with sport have mainly focused on participation rather than spectatorship (Jackson \& Csikszentmihalyi, 1999; Kawabata \& Evans, 2016). This lack of focus on spectatorship is significant, as the concept of flow inherently relates to well-being (Csikszentmihalyi, 1990) and hence understanding this concept can address the central question of how sport spectatorship is linked to positive psychological consequences, as investigated in the recent sport management literature (Doyle et al., 2016; Inoue et al., 2015). Third, we attempt to improve and diversify the existing methods in sport management by employing the implicit association test (IAT) as a measurement tool of iTeam ID. IAT is a new class of response-time-based measurement 
designed to overcome the drawbacks of survey-based self-report rating scales (e.g., response biases; Greenwald, Poehlman, Uhlmann, \& Banaji, 2009).

\section{Theoretical Background}

\section{The Concept of Implicit Team Identification (iTeam ID)}

There have been significant advances in understanding how and why fans maintain psychological connections with teams. In particular, team ID has evolved into a core construct that explains fan behavior in the context of spectator sports (Jang, Ko, Wann, \& Kim, 2017; Lock, Funk, Doyle, \& McDonald, 2014). For example, on the basis of the social identity theory, the unidimensional concept of team ID as defined by a sense of belonging (Wann \& Branscombe, 1990) and a mental representation of the self (Branscombe \& Wann, 1992) has been classified into multi-dimensional facets (such as cognitive awareness, private and public evaluation, interconnection of self, sense of interdependence, and behavioral involvement; Lock et al., 2014). In addition, scholars have advanced the conceptual richness of team ID by integrating the psychological continuum model (Funk \& James, 2001, 2006) and the fan attitude network model (Funk \& James, 2004). The predictive validity and the abundant nomological network of the team ID construct have been firmly established in the realm of sport management; recent examples include studies that show that fans with strong team ID experience greater emotional support from other fans, greater happiness in accordance with their team's victories, and greater satisfaction with their life (Inoue et al., 2017; Jang et al., 2017).

The current understanding of team ID, although informative, may be further extended when considering the theories of metacognition in cognitive psychology (Alter \& Oppenheimer, 2009; Gawronski \& Bodenhausen, 2006). According to these theoretical approaches, there are two cognitive phases that individuals process based upon stimuli input, including associative 
evaluation and propositional reasoning. Associative evaluations result from automatically activated association formations that often exist outside of a person's awareness. On the other hand, propositional reasoning develops from the logical reasoning of which the individual is aware and whose expression can be consciously controlled. In most disciplines, including sport management, the use of the term identification refers only to the cognitive outcomes of propositional reasoning operated in a conscious mode, and thus are measurable through the use of direct measures such as self-report rating scales (Lock et al., 2014; Wann \& Branscombe, 1990). In the last two decades, however, there has been a clear shift toward recognizing the pervasive role of automatic processes in predicting behavior (Alter \& Oppenheimer, 2009; Greenwald et al., 2009).

Associative evaluations are unconsciously and implicitly activated processes in a consumer's memory when the consumer encounters stimuli (Gawronski \& Bodenhausen, 2006). For example, in the case of fans of the New York Yankees, encountering words or images related to baseball (or any relevant stimuli) makes associated nodes of information relevant to the Yankees stored in fans' memory to automatically become activated (e.g., winning records, star players, or their past spectating experiences). These nodes are pieces of information connected through associative links, and each node is a potential source of activation for all associated nodes. As such, the stronger the association, the more likely of it being retrieved from memory via the spreading activation process that underpins mental maps (Alter \& Oppenheimer, 2009). Following a similar logic, in the case of fans who strongly identify with the Yankees, identification referent stimuli (e.g., the words 'we' and 'us') should be strongly associated with the Yankees referent stimuli (e.g., team name, logo, and mascot) in their memory. That is, in admitting the pair of information (e.g., we - Yankees), they will require less cognitive effort, will 
have greater processing fluency, and thus will show shorter response latency. Based on this understanding, by adopting the implicit (unconscious/associative evaluation) and explicit (conscious/propositional reasoning) dichotomy (Gawronski \& Bodenhausen, 2006), iTeam ID can be defined as individuals' stable representation of self-concept with a particular sport team, which is shaped without conscious awareness but that stems from long-term membership experiences with the team.

\section{Spectators' Flow Experiences and iTeam ID}

Spectators often experience time distortion, detachment from their surroundings, and a loss of self-consciousness due to their excessive concentration and absorption into a game. That is, while watching sporting events, fans tend to devote much time and psycho-physiological resources to the watching activities just for the sake of intrinsic enjoyment without expecting any associated external rewards (Csikszentmihalyi, 1990). Such experiential states are termed as "being in flow" (Csikszentmihalyi, 1990). The flow experience is defined as "the state in which people are so involved in an activity that nothing else seems to matter; the experience itself is so enjoyable that people will do it even at great cost, for the sheer sake of doing it" (Csikszentmihalyi, 1990, p. 4). According to the flow concept applied in sport and physical activity (Jackson \& Csikszentmihalyi, 1999; Kawabata \& Evans, 2016), the flow experience possesses a variety of dimensions including balance of knowledge/skills and challenges, total concentration on the task at hand, loss of self-consciousness, and time distortion in which time is perceived as slower or faster than normal. The flow experience often produces positive outcomes such as consumption satisfaction, repeat patronage (Richard \& Chebat, 2016), and increased quality of life (Asakawa, 2010). These effects occur because the flow experience provides such 
intrinsic enjoyment that people are ready to perform the same actions repeatedly (Jackson \& Csikszentmihalyi, 1999).

In the context of spectator sports, the spectators' implicit identification with teams (i.e., iTeam ID) seemingly shares common denominators with the variation in flow: full engagement, deep involvement, and devoted motivation (Asakawa, 2010; Csikszentmihalyi, 1990).

Additionally, flow is often experienced as part of our unconscious and implicit processes (Csikszentmihalyi, 1990; Peterson et al., 2005). Similarly, identity-based mental processes toward cues that guide subsequent behaviors often operate in the absence of conscious awareness (Oyserman, 2009). This occurs because such mental processes are governed by the working memory in the brain (Liu, 2016) in which the effortless nature of identity-based processing enables more cognitive resources to be directed toward a concurrent task (Tacikowski et al., 2017). Therefore, those who have stronger iTeam ID may be more likely to experience the flow state when watching their team's game than those who have weaker iTeam ID. Supporting this argument, Oyserman (2009) suggested that individuals are attentionally vigilant toward cues that are identity-consistent while being less attentive toward those that are inconsistent. Accordingly, it is predicted that team identification formed through automatic and associative evaluation may largely account for the state of being in flow.

H1: Implicit team identification (iTeam ID) positively influences spectators' flow experiences.

\section{Emotions and Flow}

Being in flow may be a phenomenologically unique psychological state in the domain of sport (Jackson \& Csikszentmihalyi, 1999), presumably because of the emotional dynamics this pastime provides to fans (Madrigal \& Chen, 2008). Emotions refer to valenced affective 
reactions to situations (Coleman \& Williams, 2013). From the neurobiological point of view, affective responses to and adaptation to environments (e.g., fear and happiness) are a fundamental part of human nature (Wilson, 1978). Accordingly, the importance of understanding emotions in the sphere of consumer behavior has also been firmly established (Coleman \& Williams, 2013). Products or situations that evoke emotions attract subliminal and exclusive consumer attention, which, in turn, largely contributes to subsequent consumption behavior (Coleman \& Williams, 2013).

Within spectator sports, the affective disposition theory (Raney, 2003) has been frequently applied because it pertains to the emotional reactions exhibited in viewership. When the basic assumptions of this theory are applied to the sport context first, individuals' feelings and their attachments toward a team can be considered as their affective dispositions commonly understood as fanship. Sport fans often experience various types of emotional states depending on the strength of their fanship toward a team (Madrigal \& Chen, 2008). For example, when their team performs well, the fans' intensive and positive emotions (such as happiness) may increase (Jang et al., 2017), while negative emotions (such as anger) may decrease (Uhrich \& Benkenstein, 2010). In sum, the affective disposition theory predicts that sports fans' emotional reactions will vary as a function of their affective dispositions to the parties involved in the game.

By definition, flow has been found to be associated with positive emotions rather than negative ones (Hamann, 2012). The fact that flow is a state of effortless attention which arises primarily through positive affect has been well documented (Jackson \& Csikszentmihalyi, 1999). For example, events that evoke enjoyment have been generally found to contribute to the loss of self-consciousness and to time distortion (Hamann, 2012). On the other hand, such events which 
elicit negative emotions inhibit flow (Hamann, 2012). Asakawa (2010) also suggested that there is a negative correlation between flow proneness and anxiety. Accordingly, and quite simply, events that evoke positive emotions are likely to produce flow regardless of the level of iTeam ID. This straightforward effect could be related to humans' general tendency for pursuing a positive psychological state of well-being (Asakawa, 2010).

H2: Positive emotions positively influence spectators' flow experiences, while negative emotions negatively influence their flow experiences.

\section{iTeam ID and Negative Emotions}

The entire set of emotional responses during viewership, however, may not be fully reducible to a disposition-event match. In other words, although the affective disposition theory may account for the isolated or initial emotional responses to events in sport spectatorship, the implications of the opponent process theory (Solomon \& Corbit, 1974) might be necessary to understand the effects of emotional fluctuations on spectators' flow experiences in response to a succession of events. The opponent process theory was proposed by Solomon and Corbit (1974) to account for the affective changes that take place sequentially in reaction to emotion-inducing events or objects. A seesaw serves as a useful metaphor to illustrate how the opponent process theory operates. Following this seesaw metaphor, the plank represents the emotion regulation system that accounts for humans' inherent desire for emotional equilibrium; the seat on the left represents negative emotions (e.g., anxiety), and the seat on the right represents positive emotions (e.g., happiness). Accordingly, the less the anxiety an individual experiences, the greater the happiness the individual feels, and vice versa. In the context of spectator sports, therefore, watching a favorite team's scoring success might induce sudden happiness, which, as the theory asserts, requires the suppression of opposite feelings such as fear and anxiety. Later in 
time, however, to restore the affective equilibrium, the opposite emotion (i.e., anxiety) emerges spontaneously once the happiness-eliciting stimulus has disappeared (for instance, if the viewers' favorite team fails to score or the opposite team succeeds in scoring).

With the opponent process theory (Solomon \& Corbit, 1974) it is also suggested that, through the repetition of the same or similar emotional experiences, the initial emotional reactions decrease in intensity while the opponent process is reinforced. For example, in a football game, the happiness and excitement that emerge from a touchdown by a fan's preferred team may likely decrease in power with each consecutive touchdown. Instead, fans often feel extreme happiness and enjoyment when they watch their preferred team score soon after the opposing team scores. As such, the repetitive success of the team they support (e.g., continued touchdowns) may not necessarily augment spectators' flow experiences. Paradoxically, the feelings of narcissistic relief and happiness experienced right after the end of panicky failures could be one of the major sources for viewers' flow experiences. Similarly, according to the positive view of stress, which is referred to as eustress, negative emotions elicited by certain events could be perceived positively (e.g., a threat is perceived as a positive challenge). Such positive interpretations of stressful situations have been suggested to act as a key motivational factor in spectators' consumption behavior (Trail \& James, 2001; Wann, 1995).

This paradoxical effect of the reinforced opponent process along with the satiation of positive emotions may then account for the moderating effects of emotions on the relationship between iTeam ID and flow. That is, even unfavorable events that evoke negative emotions may positively contribute to strongly identified fans' flow experiences, considering their cumulative and repetitive experiences with their favorite teams. Supporting this assumption, researchers who have studied flow (e.g., Csikszentmihalyi, 1990) suggest that individuals with high levels of 
skills, knowledge, engagement, and experience should be confronted with similarly high levels of challenge and emotional stress to experience an optimal level of flow. Because repetitive experiences of similar valences of emotions are likely to evoke boredom or tedium, such negative affect then increases the gaps between their optimal and actual stimulation levels, which in turn hinders their flow experiences (Csikszentmihalyi, 1990). As such, while watching sporting events, the feelings of negative emotions (such as anger and fear) might help optimize their desired arousal level as well as flow experiences for spectators with stronger iTeam ID.

H3: iTeam ID positively influences spectators' flow experiences even in the negative emotions-evoking events.

\section{Behavioral Consequences of Flow}

Being in flow produces positive outcomes such as personal growth and quality of life (Asakawa, 2010; Jackson \& Csikszentmihalyi, 1999). Those who have experienced flow are more likely to be actively and fully engaged in daily life and to show higher self-esteem, lower anxiety, and a stronger motivation to pursue a meaningful life (Asakawa, 2010). Accordingly, spectators who experience flow more often during a game may also show a strong desire for attending future games that would provide a similar experience; they are also more likely to spread positive word-of-mouth (WOM) about the games to friends, family, and significant others. Even spectators who experience flow due to negative emotion-eliciting events during a game may also exhibit similar patterns of consumption consequences. This prediction is based on the idea that negativity bias diminishes over time parallel to the decreasing motivation for informational processing and the increasing motivation for psychological well-being (Xing \& Isaacowitz, 2006). In other words, despite the potency and intensity of negative events that render these events attentionally and elaboratively privileged, the ongoing need to sustain a 
positive well-being might accelerate the weakening of the events' negative effects over time. As such, the general tendency for positive norm expectations and the need to pursue a positive wellbeing will lead to the erosion of specific negative information but remain as favorable memories associated with flow experiences (Jackson \& Csikszentmihalyi, 1999).

H4: Enhanced flow experiences formed through iTeam ID and emotion-evoking events positively influence spectators' future revisit intentions and WOM recommendation intentions.

\section{Method}

\section{Participants and Design}

The purpose of the current experiment was to test the predictions of how iTeam ID interacts with emotions to result in a greater likelihood of the flow experience and also affects subsequent sport fan consumption (see Figure 1). Consumers' retrospective evaluations were utilized as a form of experience sampling method. That is, we investigated spectators' current evaluations of past emotional and flow experiences related to a college football team's regular season games during the previous season. The term "experience sampling" refers to a set of empirical methods designed to allow respondents to indicate their thoughts, behaviors, and/or any physiological markers, including emotions and flow experiences, outside the walls of a laboratory and within the context of actual and everyday spectator experiences (Larson \& Csikszentmihalyi, 1983). The experience sampling method is often interchangeably referred to as ecological momentary assessment due to its powerful external validity to account for a range of psychological phenomena (Csikszentmihalyi \& Hunter, 2003). Notably, due to the characteristics of flow experiences (i.e., unforced, effortless, and unconscious concentration), experience sampling has been frequently utilized to measure flow because participants' reports only yield 
information that they are able to represent in conscious awareness at the moment when the reports are made (Csikszentmihalyi \& Hunter, 2003; Larson \& Csikszentmihalyi, 1983).

The current study recruited a panel of consumers through Qualtrics

(http://www.qualtrics.com/) with set qualifications: (1) spectators who support, to some degree, a particular American collegiate football team, and (2) spectators who attended a game with their preferred team at least once in the past year. An online survey was distributed to a total of 1,427 spectators following the target team's regular season finale, and 821 spectators participated in the survey.

\section{Procedure}

Once participants accepted the invitation, the iTeam ID measure was introduced and participants were asked to complete the task. The researchers developed a team identification implicit association test (Team ID IAT) by modifying the brief version (Chang \& Ko, 2016) of a single target implicit association test (ST-IAT; Bluemke \& Friese, 2008). The IAT is a computerized reaction-time task that measures the relative strength of automatic associations between target concepts and attribute concepts. For example, for a person with strong identification with the New York Yankees, the associative evaluation process is likely to be more fluent (i.e., quick and easy) when the mention of "Yankees" is paired with $u s$-referent words such as we and us, as opposed to when the word "Yankees" is paired with them-referent words such as they and them. In this example, the Yankees are the target concept while the $u s$ - and them-referent words are attribute concepts. Hence, the response latency difference provides a comparative and numerical estimation of the implicit team identification towards the Yankees.

The Team ID IAT was programmed and presented by the INQUISIT millisecond online software package (Inquisit $5 \mathrm{Web}$; https://www.millisecond.com). Stimuli of the Team ID IAT 
used in the current study included: (1) four pictures of a target team in which the team's logo or mascot was displayed, (2) four us-referent words including we, our, ours, and ourselves, and (3) four them-referent words including they, their, theirs, and themselves. The target concept was the name of a target team. The Team ID IAT was comprised of three separate blocks including one practice block and a pair of combined-task blocks. In the first block, participants practiced classifying the eight words into "us" and "them" categories by pressing the keys "e" or "i." Within the two combined-task blocks (i.e., the $2^{\text {nd }}$ and $3^{\text {rd }}$ blocks), if the target concept was grouped with the "us" category in the $2^{\text {nd }}$ block, the target concept was grouped with the "them" category in the $3^{\text {rd }}$ block, and the order of the $2^{\text {nd }}$ and $3^{\text {rd }}$ blocks was counterbalanced across participants.

Once participants had completed the Team ID IAT, they began the emotion manipulation task. Based on existing study (Ekman, 1992), the current work utilized a total of six emotions by specifying the negative emotions into sadness, anger, disgust, and fear, in addition to the positive emotion of happiness and with a neutral emotion serving as a control. Using the randomizer tool on Qualtrics, participants were randomly assigned to one of the six emotion manipulation conditions - between-subjects design. The experience sampling approach utilizes episodic and experiential responses by obtaining participants' reports that indicate the extent to which they experienced a range of a specific emotional state at the time of the assessment (Larson \& Csikszentmihalyi, 1983).

In each condition, the participants completed a writing task in which they were asked to remember and write about a specific situation, event, or moment that would elicit a randomly assigned emotional state while spectating the target team's game. They were also informed that the moment should only be related to the game itself (e.g., the process of taking away or 
allowing field goals, touchdowns, offense fouls, penalties, etc.). For the neutral emotion condition, the participants were asked to come up with five advantages and disadvantages of both online and the offline payment methods in spectator sports, respectively. To aid their retrospective memory of a particular emotion and as a supplement, universal facial expressions representing a randomly selected emotional state were adopted from the existing study (Kohler, 2003).

Once participants had completed the writing task, they were immediately asked to respond to the measure of the extent to which they experienced emotions (Coleman \& Williams, 2013) including anger ("frustrated", "angry", and "irritated"), disgust ("repulsive", "sick", “disgusted"), fear (“scared", "afraid”, and "panicky"), sadness (“depressed", "sad”, and "miserable"), and happiness ("happy", "pleased", and "joyful"). The format of this instrument was a seven-point scale $(1=$ not at all, 7 = extremely; Coleman $\&$ Williams, 2013). Flow was measured by adopting and modifying the existing four seven-point scale items ("felt like I was totally absorbed into the game", "time seemed to go very quickly", "forgot about my immediate surroundings", and "not conscious of how long I had been watching"; Richard \& Chebat, 2016). Future attendance ("intention to attend games that would bring a similar experience"; Fink, Cunningham, \& Kensicki, 2004) and WOM Recommendation Intention (“intention to recommend attending future games to important others") were measured by using the three seven-point scale formats, respectively $(1=$ very unlikely, $7=$ very likely; $1=$ definitely would not, 7 = definitively; and $1=$ strongly uninterested, $7=$ strongly interested .

Participants were then asked to provide open-ended responses to the following questions: the name of their preferred team, the opponent team at the game they attended, the athletic conference in which the teams are involved, the specific date of the game they attended, the 
name of the stadium where they attended, and the final score of the game (along with the name of the winning team). Two screening items (Downs, Holbrook, Sheng, \& Cranor, 2010) were added to filter out inattentive or non-engaged participants. At the end of the survey, participants were thanked and fully debriefed.

\section{Results}

\section{Preliminary Analyses}

Although the original sample contained 821 spectators who participated in the online experiment, the final sample contained 641 participants due to the removal of 64 individuals who provided incomplete responses, 78 who failed the two screening questions, and 38 who failed to provide or provided incorrect information about a match (e.g., the name of the opponent team and the winning team were inconsistent). With respect to sample characteristics, approximately $61 \%$ of the participants were male $(n=393)$. The majority of participants were in the $18-30(n=$ $254,40 \%)$ or $31-50(n=253,39 \%)$ age ranges, were White/Caucasian $(n=444,69 \%)$, and had at least a Bachelor's degree $(n=494,77 \%)$, with about $50 \%$ of the participants $(n=322)$ reporting an annual income between $\$ 40,000-\$ 69,999$ and $37 \%(n=238)$ between $\$ 70,000$ $\$ 120,000$. Compared to information provided by the U.S. Census Bureau (2016), our sample may not represent the general population residing in the U.S (e.g., our sample was younger, with the bureau reporting $62 \%$ of the U.S. population in the 19-64 age range). However, our sample was deemed representative of the larger North American sport fan population, as the demographic characteristics of the sample were in line with those reported by Scarborough Sports Marketing (as published in Street \& Smith’s SportsBusiness Daily, 2010).

Emotion manipulations were checked through the survey measures of emotions assessed immediately after the writing task of retrospective spectating experiences. The items measuring 
Anger (three items; $\alpha=.90$ ), Disgust (three items; $\alpha=.87$ ), Fear (three items; $\alpha=.94$ ), Sadness (three items; $\alpha=.91$ ), and Happiness (three items; $\alpha=.91$ ) as well as a global Negative emotion including the four specific negative emotions (i.e., 12 items; Anger, Disgust, Fear, and Sadness; $\alpha=.83)$ were all averaged to designate a single measure for each variable. A series of multivariate analysis of variance (MANOVA) along with follow-up univariate $F$ tests were conducted. In sum, the emotion manipulations were successful. For example, after breaking down the Negative emotions into four specific emotion profiles, the results indicated the acceptable validity of the emotion manipulations given the significant differences on the emotional responses (Pillai's Trace $=1.18, F(25,635)=39.38, p<.001$ ). The univariate $F$ test also revealed that all of the emotion manipulation conditions showed the highest emotional responses for their respective emotion. For example, Anger was significantly high in the Anger condition $(M=5.65, F(5,635)=159.3, p<.001)$, followed by Disgust $(M=4.20)$, Fear $(M=$ 3.96), Sadness $(M=3.45)$, Happiness $(M=3.23)$, and Neutral $(M=2.63)$.

With respect to iTeam ID measured through the Team ID IAT, we recoded latencies below 300 milliseconds and above 3000 milliseconds to the respective values, and, by following existing suggestions, dropped the first trial of each block to control latency variability (Bluemke $\&$ Friese, 2008). Additionally, iTeam ID was estimated by subtracting the mean latency in the target team-us block from the target team-them block. Thus, the higher the score, the higher an individual's implicit identification with the target team. A split-half internal consistency revealed an acceptable reliability $(\alpha=.81)$ and low mean error rates (3.89\%) (Bluemke \& Friese, 2008).

\section{Main Analyses}

iTeam ID and emotions on flow. Generalized linear models (GLM) along with analyses of variance (ANOVAs) were used to test the main and interaction effects of iTeam ID and 
emotions on flow. The multiple items measuring Flow $(\alpha=.93)$ were averaged to designate a single measure, and were then standardized to directly compare them to iTeam ID obtained through Team ID IAT. The results revealed that iTeam ID significantly influenced Flow $(\beta=.65$, $\mathrm{SE}=.17, t=3.83, p<.001)$. Thus, the stronger the spectators' iTeam ID, the greater their likelihood to experience flow, which supported H1. Emotions also significantly influenced Flow (Negative vs. Neutral vs. Positive; $F(2,638)=12.23, p<.001)$. The Positive Emotion condition exerted the highest level of Flow $(M=.45)$, followed by Neutral $(M=-.079)$ and Negative $(M=$ -.082) emotions. These results supported $H 2$.

Regarding $H 3$, after categorizing the negative emotions into four specific emotion profiles, the results yielded a significant iTeam ID $\times$ Emotions (Anger vs. Disgust vs. Fear vs. Sadness vs. Neutral vs. Positive) interaction for Flow, $F(5,629)=3.04, p=.01$. Specifically, the emotions of Anger, Fear, and Sadness interacted with iTeam ID in affecting Flow: the stronger the participants' iTeam ID, the higher their likelihood to experience Flow in the Anger $(\beta=.63$, $\mathrm{SE}=.34, t=1.87, p=.04)$, Fear $(\beta=1.35, \mathrm{SE}=.40, t=3.38, p<.001)$, and Sadness $(\beta=1.04$, $\mathrm{SE}=.51, t=2.06, p=.04)$ conditions. However, there were nonsignificant influences of iTeam ID on Flow in the Disgust condition $(\beta=-.69, \mathrm{SE}=.45, t=-1.52, p=.13)$. Accordingly, $H 3$ is supported by the three negative emotions of Anger, Fear, and Sadness, but not by Disgust. Figure 2 summarizes the results of the interaction effects of iTeam ID and Emotions on Flow.

iTeam ID, emotions, and flow on revisit and WOM intentions. To test the moderated mediation effects of iTeam ID (predictor), three emotional categories of Negative, Neutral, and Positive (moderator), and Flow (mediator) on Revisit Intention (predicted) and WOM Recommendation Intention (predicted), we performed multiple group structural equation modeling (MGSEM) with the bias-corrected bootstrap method. The results showed an acceptable 
fit to the data $\left(\chi^{2} / \mathrm{df}=271.87 / 117=2.32, \mathrm{CFI}=.97, \mathrm{TLI}=.96, \mathrm{RMSEA}=.07, \mathrm{SRMR}=.03\right)$. The measurement invariance test showed no substantial difference in the factor structures of the measurement across groups when compared to the CFI and RMSEA between the configural model and factor loadings constraint model $(\triangle \mathrm{CFI}=.004$ and $\triangle \mathrm{RMSEA}=.001)$. Given the acceptable model fits and the invariant measurement model, the structural invariance test demonstrated that the causal links significantly differ among the three emotion conditions $\left(\Delta \chi^{2}\right.$ $[5]=14.86, p=.01)$.

In support of $H 4$ (i.e., the predictive validity of Flow on subsequent sport fan consumption), Flow significantly influenced Revisit (e.g., $\beta=.19, \mathrm{SE}=.05, p<.001$ for the Negative Emotion condition) and WOM Intentions (e.g., $\beta=.34, \mathrm{SE}=.12, p=.003$ for the Positive Emotion condition). Additionally, Flow partially mediated the relationship between iTeam ID and Revisit and WOM in the Negative Emotion condition (total effects on Revisit: $\beta$ $=.21$, S.E.boot $=.05, \mathrm{CI}: .11, .32, p<.001$; total effects on WOM: $\beta=.17$, S.E.boot $=.05$, CI: $.07, .28, p=.001)$. However, there were nonsignificant mediation effects in the Positive Emotion condition (total effects on Revisit: $\beta=.06$, S.E.boot $=.12, \mathrm{CI}:-.17, .30, p=.60$; total effects on WOM: $\beta=-.04$, S.E.boot $=.10, \mathrm{CI}:-.21, .18, p=.74)$. These results provided further supports for the direct effects of iTeam ID on Flow (H1), universal appeal of Positive Emotions (H2), and the paradoxical effects of Negative Emotions for spectators with a strong iTeam ID (H3). Table 1 and Figure 3 display a summary of the MGSEM results.

\section{Discussion}

\section{Theoretical Implications}

The concept of implicit team identification (iTeam ID) and its explanatory power. 
The results supported the empirical robustness and nomological validity of the concept of iTeam ID. The suggested concept and measurement of iTeam ID may shed new light in the existing literature. First, implicitly and unconsciously shaped team ID, compared to conscious and explicit one, may better account for the state of being in flow. Flow is a state experienced outside of conscious awareness or control (Csikszentmihalyi, 1990; Peterson et al., 2005). Similarly, identity-based mental processes have been suggested to occur in the absence of conscious awareness (Oyserman, 2009) because identity-relevant cues capture preconscious attention, which, in turn, engenders consumers to use mental procedures congruent with their identity (Oyserman, 2009). Social psychologists (Tacikowski et al., 2017) have characterized such mental processes as cue sensitivity, alertness, and vigilance stemming from inherent human nature of self-actualization and self-defense as a social member of stigmatized groups. For example, Tacikowski et al. (2017) compared self-directed and other-directed mental processes, and suggested that the information processing of such self-related stimuli is relatively far less cognitively demanding and effortful, and interfered by other information cues. Therefore, given the large explanatory power of iTeam ID on flow grounded on the equivalent mental mechanism of unconscious and automatic processing, as well as the lack of research exploring the antecedents of flow in the viewership literature, the results of the current study provide a viable determinant in predicting spectators' flow state.

Second, the majority of existing identification research is primarily reliant on explicit and self-report rating scales of team ID, including both unidimensional (Wann \& Branscombe, 1990) and multidimensional forms (Lock et al., 2014). The underlying assumption behind those scales could be that fans are willing to consciously and deliberately think about the extent to which they identify with teams and are able to precisely report their identification level. However, these 
conditions may not always meet, as fans may not want to report or may even be unaware of their accurate level of identification with teams. Cognitive psychologists (Alter \& Oppenheimer, 2009; Gawronski \& Bodenhausen, 2006) have suggested that propositional reasoning can be characterized as a series of fast-changing mental processes because it is susceptible to environmental changes and new information (e.g., recent winning/losing records or scandals of players). Overcoming such response and cognitive biases, the outcomes of associative evaluations provide access to fans' relatively stable and constant responses because these responses are shaped through fans' cumulative socialization processes (Alter \& Oppenheimer, 2009; Gawronski \& Bodenhausen, 2006). Additionally, respondents are generally unaware of the measurement attempt of the Team ID IAT utilizing the response-time-based measurement tool. Nevertheless, as Greenwald et al. (2009) suggested, future research may extend the current study through the joint application of conscious and unconscious levels of team identification, as these two factors may display incremental validity (relatively momentary for the explicit measure, while relatively long-lasting for the implicit measure) in explaining actual spectating behavior.

iTeam ID: Interaction with positive emotions. Social identities are highly sensitive to emotional cues given that identities are not merely collections of attitudes, beliefs, and behaviors, but also consist of connections to specific emotional states (Coleman \& Williams, 2013; Oyserman, 2009). For example, Grol, Koster, Bruyneel, and Raedt (2014) showed the null effect of identity-relevant cues as well as the interplay of identity and the state of mood in predicting attention and behaviors. Additionally, emotion largely accounts for the flow state (Larson \& Csikszentmihalyi, 1983; Richard \& Chebat, 2016), given that emotion has been found to govern the cognitive processes of reasoning, memory, and attention (Johnson-Laird \& Oatley, 2014). Sport fans often assign a different weight to each moment of their experience based on their 
particular emotional state elicited by this experience (Kim, Magnusen, \& Lee, 2017), which then becomes a significant predictor of future behavior for a similar experience (Doyle et al., 2016). As such, by interplaying with iTeam ID, our results provided evidence that the state of being in flow dynamically fluctuated corresponding to a variety of emotions-eliciting events.

The general tenet of flow is positively associated with positive emotions (Csikszentmihalyi \& Hunter, 2003; Jackson \& Csikszentmihalyi, 1999). For example, events that evoke positive emotions (e.g., enjoyment), rather than negative emotions, contribute to flow experience such as loss of self-consciousness and time distortion (Hamann, 2012). This general understanding of flow was considered in the current study because the implicit identification effect could not override mere correlations. In other words, regardless of the level of iTeam ID, spectators showed a higher level of flow experience on the happiness-evoking condition. The results of MGSEM also showed nonsignificant direct effects of iTeam ID on both future attendance and WOM in the happiness conditions, thereby reflecting the universal appeal of positive emotions. The major consequences of feeling happiness include continuing the current attention and behaviors (Johnson-Laird \& Oatley, 2014) such as unconscious concentration on what the individuals are watching (i.e., flow) or revisiting and referring to a site that is expected to provide similar experiences (Madrigal \& Chen, 2008).

iTeam ID: Interaction with negative emotions. However, interestingly, the results also revealed the interaction effects of iTeam ID with several negative emotions on flow. That is, anger, fear, and sadness still interfered with the flow experience for those participants who expressed weaker iTeam ID, while the three negative emotions positively intensified the state of flow for spectators who showed a stronger iTeam ID. Similarly, the results of MGSEM showed 
that the negative emotion condition (in addition to neutral emotion) exerted significant direct effects of iTeam ID on both the revisit and WOM intentions.

The three negative emotions of anger, fear, and sadness have been found to share similar psychological and physiological characteristics. For example, anger has been found to be part of the grief and sadness process, which, in turn, positively influences fear, worry, and anxiety (Stroebe \& Archer, 2013). The outcomes of a certain degree of these three negative emotions similarly include increased respiration, heart rate, and blood pressure (Thayer, Ahs, Fredrikson, Sollers, \& Wager, 2012). Additionally, according to the brain map of arousal in neuropsychology (Hamann, 2012), these three negative emotions represent moderate levels of arousal in contrast to the feeling of disgust. That is, disgust represents the highest arousal level, followed by fear (high moderate), anger (about moderate), and sadness (low moderate). As such, the feeling of disgust has been found to be distinctive, as it occurs even without an object (Johnson-Laird \& Oatley, 2014), serving individuals' defensive needs (Westphal, Bonanno, \& Mancini, 2014), and producing aversion behaviors (such as attentional away; Westphal et al., 2014). With respect to the relationship with flow, being in flow has been characterized as having an increased heart rate, higher blood pressure, and heart rate variability (Csikszentmihalyi, 1990; Jackson \& Csikszentmihalyi, 1999), all of which share similar physiological characteristics with the three negative emotions of anger, fear, and sadness. The flow experience also largely comes along with a moderate level of arousal, while both excessively low (i.e., boredom) and excessively high (i.e., stress) levels of arousal can interfere with flow (Jackson \& Csikszentmihalyi, 1999). Hence, fear, anger, and sadness may represent appropriate levels of arousal in producing the flow state.

These results also supported the opponent process theory. As discussed earlier, this theory accounts for the changing intensity of emotional reactions through repeated exposures to 
the same stimuli, which, in turn, widens the motivational implications of the opponent process (Solomon \& Corbit, 1974). This gradual and counterintuitive association of the opposite feeling (Markowitz \& Arent, 2010) may account for the strongly identified spectators' flow experiences toward negative emotions-eliciting events. That is, after experiencing the same or similar stimuli repeatedly (e.g., continued scoring success of a favorite team), perceived arousal from each occasion decreases because fans start to perceive a negative affect such as boredom or tedium (Csikszentmihalyi, 1990). Subsequently, fans may seek novel stimuli to achieve arousal closer to their optimal level (Ein-Gar et al., 2012; Redden \& Galak, 2013). As such, spectators with stronger iTeam ID might utilize the feelings of anger, fear, and sadness to optimize their arousal level. Despite the anger, fear, and sadness experienced by spectators who strongly identified with a team, the expected after-feeling of egotistical relief or happiness (e.g., sudden scoring success of their favorite teams) might be increasingly associated with the state of flow. In other words, by watching a game with a close score, fans often prefer to feel suspense and anxiety rather than boredom. This association might, in turn, constitute the main source of motivation to spectate in the future and to give WOM recommendations to others as the initial negative feelings weaken over time (Xing \& Isaacowitz, 2006). Similarly, negative emotions have also been found to positively contribute to consumption satisfaction and future attendance (Su-lin et al., 1997).

The positive psychology approach applied in the sport management literature (e.g., Doyle et al., 2016) also supports the results. The positive view of stress (i.e., eustress) represents a key motivational factor of spectators' consumption behavior (Trail \& James, 2001; Wann, 1995). Similarly, spectators' consumption behavior increases according to the uncertainty of expected game outcomes (Hogan et al., 2017). Spectator experiences are enjoyable and memorable, and fans can arouse a sense of stimulations when watching a dramatic and close game (Trail \& 
James, 2001). That is, sporting events are characterized as competitions that are unpredictable and unstable in nature because they consist of multiple events that induce negative emotions such as the scoring failures of fans' favorite teams and the opposite team's scoring successes. Counterintuitively, engaging in these stress-inducing and negative emotions-eliciting moments simultaneously entails favorable outcomes such as the flow state and life satisfaction (Csikszentmihalyi, 1990; Jackson \& Csikszentmihalyi, 1999). For example, according to the functional elements of flow (Csikszentmihalyi, 1990), individuals with high levels of skills and knowledge are likely to experience high concentration when they come across optimally challenged and stressful tasks. Similarly, anger and fear heightens attention and sensitivity to the environment, and the expression of such emotions indicates stronger identification with an attitude object (Overall, Fletcher, Simpson, \& Fillo, 2015). Experiencing a certain level of negative emotion produces proportionate heart rate variability, which can prevent depression and sickness (Thayer et al., 2012).

The consequential effects of flow. The concept of flow has been extensively researched in a variety of sport contexts. However, most of those studies (e.g., Jackson \& Csikszentmihalyi, 1999; Kawabata \& Evans, 2016) have focused on sport participation rather than spectatorship. Accordingly, the consequential effects of flow found in the current study are especially meaningful considering the following two contributions: the results support (1) the plausibility of the contextual expansion of the flow concept to the spectator sport and (2) spectators indeed value their flow experience and consider it for future consumption. Specifically, the results of MGSEM revealed the positive direct effects of flow on both the revisit and WOM recommendation intentions in all conditions. That is, the more participants experience flow, the 
higher the likelihood of their future attendance and WOM recommendation in spite of the retrospective memories of positive or even negative emotional experiences.

These results support existing flow and spectatorship studies. For example, individuals who experience the flow state during activities desire to perform the same actions repeatedly because the flow experience provides intrinsic enjoyment (Jackson \& Csikszentmihalyi, 1999). Consequently, the more individuals experience flow in activities, the greater their well-being and life satisfaction (Jackson \& Csikszentmihalyi, 1999). Doyle et al. (2016) suggested that spectator experiences help activate a variety of individual-level well-being dimensions such as positive emotions, community integrations, and accomplishment. In their review analyzing 135 empirical studies, Inoue et al. (2015) suggested the positive impacts of sport spectatorship on a variety of domains of community health such as facilitating health-related behaviors and physical, mental, and social well-being. The enhanced perceptions of subjective well-being and life satisfaction, in turn, positively influence fans' desire for continued engaging opportunities such as revisit and referral intentions (Yoshida, Gordon, Nakazawa, \& Biscala, 2014).

Interestingly, enhanced flow experiences formed through iTeam ID and negative emotion-evoking events positively contributed to spectators' future intentions of revisit and WOM recommendation. Negativity bias literature points to a faster mobilization of attentional resources (Alter \& Oppenheimer, 2009) as well as an unforced and stronger cognitive elaboration associated with negative emotions-evoking information (Ein-Gar et al., 2012). This bias may be more prominent for spectators with stronger iTeam ID because these spectators often consider such negative emotions-evoking information as identity-threatening events (Fox, Russo, Bowles, \& Dutton, 2001). However, memories containing negativity often erode easily over time due to the fundamental human nature to pursue psychological well-being (Xing \& 
Isaacowitz, 2006). In the meantime, the enhanced subjective familiarity with an attitude object (or the gist memories of such flow experiences) could remain present over time, which often results in favorable post-consumption evaluations (i.e., fluency effects moderated by negativity bias) (Alter \& Oppenheimer, 2009). The remained gist memories of flow experiences, then, go on to contribute to satisfaction, hopefulness, excitement, entertainment, and future intentions (Jackson \& Csikszentmihalyi, 1999; Richard \& Chebat, 2016).

In addition to the cognitive psychological interpretation of the results, sociopsychological reasoning may account for enhanced WOM behaviors in the negative emotion condition. Service consumers engage in WOM activities and recommend the services they used to others as a way of boosting their self-image and facilitating their social status (Lang, 2011). In the case of hedonic service encounters (e.g., attending sporting games) and compared to utilitarian ones (e.g., dry cleaning), the retrospective evaluation of consumption experiences could be more favorable, especially when consumers engage in WOM activities due to the desire not to share information (e.g., feelings of anger and fear) that could damage their ego and selfimage (Lang, 2011). For example, Sun (2014) suggested that consumers often desire to spread positive WOM in spite of having experienced psychological and social risks to show that their decisions are right, so as to protect their own self-image and obtain positive recognition from others by exclusively spreading favorable information about a product they have consumed.

\section{Practical Implications}

The results of the current study provide a basis for several managerial implications. First, iTeam ID may provide sport marketers with new insights into understanding and tracking fans' identification with teams. The unconscious nature of consumption is especially evident among sport spectators because spectatorship experiences largely provide experiential (e.g., episodic 
and extraordinary memories), emotional (e.g., happiness), and symbolic (e.g., social identity) benefits to fans. For example, fans (as well as coaches, players, and managers) often follow their intuitive judgements rather than from logically estimated winning probabilities of a game (e.g., the hot-hand fallacy). It is not uncommon to observe that fans remain loyal with unsuccessful sport franchises (e.g., Detroit Lions; Campbell, Aiken, \& Kent, 2004). Mere exposure to certain sports team mascots (e.g., Cleveland Indians) might shape individuals' implicit (dis)favorableness toward particular fan segments (Angle, 2016). As such, managers should be aware that fans can make their consumption decision and develop their preference based on their inner voices or intuitive and 'gut' level of judgments (e.g., representations of self-concept with a specific sporting team shaped from long-term membership experiences with the team).

Keeping this knowledge in mind, sport marketers should consider measuring iTeam ID for their market research to track the level of implicit ID among their fan base. As mentioned, the response-time-based measurement of iTeam ID developed through fans' unconscious process may provide managers with more consistent estimations and predictions of fan identification with teams across a variety of consumption circumstances. The creation of implicit associations with an attitude object cannot be achieved in a short-term period because such automatic associations are shaped through cumulative experiences. One effective strategy suggested in mere exposure and implicit memory literature (Alter \& Oppenheimer, 2009) is repetition, whereby teams, events, or athlete brand managers consider repeatedly exposing the association between their brands and the consumers' actual and desired identities and/or important meanings, values, and traditions which the target markets may have (e.g., Green Bay Packers and "cheese heads" identifying with the team and the state of Wisconsin; Heere \& James, 2007). In line with the Funk and James's $(2001,2006)$ seminal work, however, such mere association 
strategies may be primarily effective for increasing awareness or attracting fans' temporal attention. To fully develop iTeam ID, managers should provide more engaging and bonding opportunities (e.g., voluntary participation and reciprocal service learning opportunities; Yoshida et al., 2014). Sport marketers can monitor iTeam ID to assess the effectiveness of such strategies. Through the joint application of conscious and unconscious levels of team identification, managers will be able to develop a strong fan base and eventually increase long-term profitability. Numerous open-source software (e.g., www4.ncsu.edu/ awmeade/FreeIAT/FreeIAT.htm), online libraries (e.g., www.projectimplicit.net), and (non)-profit consulting organizations (e.g., Project Implicit and Millisecond) are available for the applications and customizations of implicit measures including iTeam ID for practitioners.

Second, sport marketers should facilitate more emotional experiences to encourage flow because experiencing flow positively influences repeat patronage and WOM recommendation. For online and television viewers, marketers may encourage experiences that produce intuitive feelings through advertisements, halftime shows, and sponsorship. A recent example includes the tale of a mother and daughter's travels featured in an image of a wall in the U.S.-Mexico border; such an image simultaneously encourages feelings of curiosity, compassion, and responsibility for spectators to continue watching the Super Bowl event. As such, television advertisements may follow a sporting event to naturally induce certain emotions or invigorate spectators' emotional experiences. The advertisements could also be tailored to resonate with the activity level of a particular emotion profile. For stadium attendants, marketers may actively utilize the specific elements of stadium atmosphere to facilitate more emotional experiences such as organizer-induced (e.g., announcers' comments and the types of background music), spectator- 
induced (e.g., crowdedness), and architecture-related stimuli (e.g., the volumes of sound and the location of bleachers) (Uhrich \& Benkenstein, 2010). Employing this strategy with a focus on merely liked or non-fans, it is recommended to make them experience exclusively positive emotions (such as happiness, fun, and enjoyment) to encourage and contribute to their flow experiences.

When targeting brand lovers or "big fans," the creation of negative emotions (in addition to positive emotions) is important to contribute to the fans' flow experience. For example, managers may actively utilize the sensory elements of stadiums, referred to as sensoryscape (Lee, Lee, Seo, \& Green, 2012) along with the stadium atmosphere (Uhrich \& Benkenstein, 2010). Specifically, designing the stands and bleachers to have high social density and a noisy crowd may positively contribute to spectators' stadium experiences by enhancing the negative emotions of thrill and anxiety (Uhrich \& Benkenstein, 2010). Similarly, background music that expresses sadness or melancholy may stimulate nostalgic memories of fanship (Taruffi \& Koelsch, 2014), which may, in turn, boost the opponent process (e.g., extreme happiness for a favorite team's sudden scoring success soon after the opponent's continued scoring successes). As such, for spectators with stronger iTeam ID, managers should not excessively worry about fans' expressions of negative emotions. Rather, such expressions of negative emotions may signal stronger identification with a team and a strong desire to maintain the relationship with that team (Overall et al., 2015). Additionally, experiencing negative emotions, as previously discussed, can even enhance unforced concentration on a game, and experiencing the contrast of such feelings simultaneously can reduce boredom and fatigue (Ein-Gar et al., 2012). The proactive management of operations corresponding to spectators' emotional responses will help 
boost spectators' flow and intrinsic enjoyment, which, in turn, ultimately contributes to the longlasting profitability of their business and the community's health and well-being.

\section{Limitations and Future Suggestions}

Future researchers should address the following limitations and suggestions. First, the utilization of spectators' retrospective responses based on an experience sampling approach has been one of the most popular ways to manipulate and measure emotions and flow, and the reliability and validity of these methods have been well-established (Csikszentmihalyi \& Hunter, 2003; Larson \& Csikszentmihalyi, 1983). However, the results should be applied with caution, as there may be numerous potential covariates that the current study could not control. For example, the respondents might have underreported or hidden significant parts of their emotional and flow experiences intentionally or unintentionally, so that the distributions of the feelings and flow found may not be fully reliable (Larson \& Csikszentmihalyi, 1983). Additionally, people are often inaccurate in reconstructing an experience after the fact, which engenders the potential of memory bias in the representation of experiences (Larson \& Csikszentmihalyi, 1983). Future research may attempt to replicate this study by addressing the aforementioned sampling and memory biases as follows: (a) prompt spectators' multiple times of experience at fixed intervals in order to gather variable data, and (b) close the gaps between the time of spectators' actual experience and the time of assessment in order to more accurately capture the representation of the spectator's experience.

Second, the current study was delimited to a particular type of spectator sports (i.e., college football consumers). Future studies may further validate the results by using a broader sampling frame in various spectator sports contexts. Third, we employed revisit intention measures as a proxy of actual returning behavior; however, intention measures inherently have a 
limited predictive validity. Accordingly, future studies may measure spectators' actual buying behaviors by examining their longitudinal purchase transaction history. Fourth, there are a number of WOM platforms that encourage consumer interactions to share information about the products they purchased. Most recently, due to its cost effectiveness, electronic WOM marketing has been actively used to promote brands. While such social media accounts are designed to encourage customers to communicate with one another in the form of WOM, this two-way communication channel could result in an increased relationship quality and brand equity. Future studies may utilize online WOM behaviors as an outcome of flow experience. 


\section{References}

Alter, A. L., \& Oppenheimer, D. M. (2009). Uniting the tribes of fluency to form a metacognitive nation. Personality and Social Psychology Review. 13, 219-235.

Angle, J. (2016, September 15). Sorry, Redskins fans: Native American mascots increase racial bias. Retrieved from https://www.washingtonpost.com/news/speaking-ofscience/wp/2016/09/15/sorry-redskins-fans-native-american-mascots-increase-yourracial-bias/?utm_term $=.4 \mathrm{ef} 428307175$

Asakawa, K. (2010). Flow experience, culture, and well-being: How do autotelic Japanese college students feel, behave, and think in their daily lives? Journal of Happiness Studies, $11,205-223$.

Bluemke, M., \& Friese, M. (2008). Reliability and validity of the single-target IAT (ST-IAT): Assessing automatic affect towards multiple attitude objects. European Journal of Social Psychology, 38, 977-997.

Branscombe, N. R., \& Wann, D. L. (1992). Role of identification with a group, arousal, categorization processes, and self-esteem in sports spectator aggression. Human Relations, 45, 1013-1033.

Campbell, R.M., Jr., Aiken, D., \& Kent, A. (2004). Beyond BIRGing and CORFing: Continuing the exploration of fan behavior. Sport Marketing Quarterly, 13, 151-157.

Chang, Y., \& Ko, Y. J. (2016). Reconsidering the role of fit in celebrity endorsement: Associative-propositional evaluation (APE) accounts of endorsement effectiveness. Psychology \& Marketing, 33, 678-691.

Coleman, N. V., \& Williams, P. (2013). Feeling like myself: Emotion profiles and social identity. Journal of Consumer Research, 40, 203-222. 
Csikszentmihalyi, M. (1990). Flow: The psychology of optimal performance. New York: Cambridge University Press.

Csikszentmihalyi, M., \& Hunter, J. (2003). Happiness in everyday life: The uses of experience sampling. Journal of Happiness Studies, 4, 185-199.

Downs, J. S., Holbrook, M. B., Sheng, S., \& Cranor, L. F. (2010). Are your participants gaming the system? Screening Mechanical Turk workers. In Proceedings of the 28th international conference on Human factors in computing systems (pp. 2399-2402). New York: ACM. doi:10.1145/1753326.1753688

Doyle, J. P., Filo, K., Lock, D., Fink, D. C., \& McDonald, H. (2016). Exploring PERMA in spectator sport: Applying positive psychology to examine the individual-level benefits of sport consumption. Sport Management Review, 19, 506-519.

Ein-Gar, D., Shiv, B., \& Tormala, Z. L. (2012). When blemishing leads to blossoming: The positive effect of negative information. Journal of Consumer Research, 38, 846-859.

Ekman, P. (1992). An argument for basic emotions. Cognition and Emotion, 6, 169-200.

Fink, J. S., Cunningham, G. B., \& Kensicki, L. J., (2004). Using athletes as endorsers to sell women's sport: Attractiveness vs. expertise. Journal of Sport Management, 18, 350-367.

Fox, E., Russo, R., Bowles, R., \& Dutton, K. (2001). Do threatening stimuli draw or hold visual attention in subclinical anxiety? Journal of Experimental Psychology: General, 130, 681700.

Funk, D., \& James, J. (2001). The psychological continuum model: A conceptual framework for understanding an individual's psychological connection to sport. Sport Management Review, 4, 119-150. 
Funk, D., \& James, J. (2004). The Fan Attitude Network (FAN) model: Exploring attitude formation and change among sport consumers. Sport Management Review, 7, 1-26.

Funk, D., \& James, J. (2006). Consumer loyalty: The meaning of attachment in the development of sport team allegiance. Journal of Sport Management, 20, 189-217.

Gawronski, B., \& Bodenhausen, G. V. (2006). Associative and propositional processes in evaluation: An integrative review of implicit and explicit attitude change. Psychological Bulletin, 132, 692-731.

Greenwald, A. G., Poehlman, T. A., Uhlmann, E. L., \& Banaji, M. R. (2009). Understanding and using the Implicit Association Test: III. Meta-analysis of predictive validity. Journal of Personality and Social Psychology, 97, 17-41.

Grol, M., Koster, E. H. W., Bruyneel, L., \& Raedt, R. D. (2014). Effects of positive mood on attention broadening for self-related information. Psychological Research, 78, 566-573.

Hamann, S. (2012). Mapping discrete and dimensional emotions onto the brain: Controversies and consensus. Trends in Cognitive Sciences, 16, 458-466.

Heere, B., \& James, J. (2007). Sports teams and their communities: Examining the influence of external group identities on team identity. Journal of Sport Management, 21, 319-337.

Hogan, V., Massey, P., \& Massey, S. (2017). Analysing match attendance in the European Rugby Cup: Does uncertainty of outcome matter in a multinational tournament? European Sport Management Quarterly, 17, 312-330.

Inoue, Y., Berg, B. K., \& Chelladurai, P. (2015). Spectator sport and population health: A scoping study. Journal of Sport Management, 29, 705-725.

Inoue, Y., Sato, M., Filo, K., Du, J., \& Funk, D. C. (2017). Sport spectatorship and life satisfaction: A multicountry investigation. Journal of Sport Management, 31, 419-432. 
Jackson, S. A., \& Csikszentmihalyi, M. (1999). Flow in sports: The keys to optimal experiences and performances. Champaign, IL: Human Kinetics.

Jang, W., Ko, Y. J., Wann, D., \& Kim, D. (2017). Does spectatorship increase happiness? The energy perspective. Journal of Sport Management. doi: http://dx.doi.org/10.1123/jsm.2016-0113

Johnson-Laird, P. N., \& Oatley, K. (2014). Cognitive approaches to emotions. Trends in Cognitive Sciences, 18, 134-140.

Kawabata, M., \& Evans, R. (2016). How to classify who experienced flow from who did not based on the flow state scale-2 scores: A pilot study of latent class factor analysis. The Sport Psychologist, 30, 267-275.

Kim, J., Kim, Y., \& Kim, D. (2016). Improving well-being through hedonic, eudaimonic, and social needs fulfillment in sport media consumption. Sport Management Review. doi: https://doi.org/10.1016/j.smr.2016.10.001

Kim, J. W., Magnusen, M., \& Lee, H. (2017). Existence of mixed emotions during consumption of a sporting event: A real-time measure approach. Journal of Sport Management. doi: http://dx.doi.org/10.1123/jsm.2016-0215

Kohler, C. G., Turner, T. H., Bilker, W. B., Brensinger, C. M., Siegel, S. J., Kanes, S. J., et al. (2003). Facial emotion recognition in schizophrenia: Intensity effects and error pattern. American Journal of Psychiatry, 160, 1768-1774.

Lang, B. (2011). How word of mouth communication varies across service encounters. Managing Service Quality: An International Journal, 21, 583-598. 
Larson, R. \& Csikszentmihalyi, M. (1983). The experience sampling method. In H. T. Reis, Naturalistic approaches to studying social interaction: new directions for methodology of social and behavioral science: No. 15. San Francisco, CA: Jossey-Bass.

Lee, S., Lee, H., Seo, W., \& Green, C. (2012). A new approach to stadium experience: The dynamics of the sensoryscape, social interaction, and sense of home. Journal of Sport Management, 26, 490-505.

Liu, D., Wang, L., Wang, Y., \& Jiang, Y. (2016). Conscious access to suppressed threatening information is modulated by working memory. Psychological Science, 27, 1419-1427.

Lock, D., Funk, D. C., Doyle, J. P., \& McDonald, H. (2014). Examining the longitudinal structure, stability, and dimensional interrelationships of team identification. Journal of Sport Management, 28, 119-135.

Madrigal, R., \& Chen, J. (2008). Moderating and mediating effects of team identification in regard to causal attributions and summary judgments following a game outcome. Journal of Sport Management, 22, 717-733.

Markowitz, S. M., \& Arent, S. M. (2010). The exercise and affect relationship: Evidence for the dual-mode model and a modified opponent process theory. Journal of Sport and Exercise Psychology, 32, 711-730.

Overall, N. C., Fletcher, G. J. O., Simpson, J. A., \& Fillo, J. (2015). Attachment insecurity, biased perceptions of romantic partners' negative emotions, and hostile relationship behavior. Journal of Personality and Social Psychology, 108, 730-749.

Oyserman, D. (2009). Identity-based motivation and consumer behavior. Journal of Consumer Psychology, 19, 276-279. 
Peterson, C., Park, N., \& Seligman, M. E. P. (2005). Orientations to happiness and life satisfaction: The full life versus the empty life. Journal of Happiness Studies, 6, 25-41.

Raney, A. A. (2003). Disposition-based theories of enjoyment. In J. Bryant, D. RoskosEwoldsen, \& J. Cantor (Eds.), Communication and emotion: Essays in honor of Dolf Zillmann (pp. 61-84). Mahwah, NJ: Lawrence Erlbaum Associates.

Redden, J. P., Galak, J. (2013). The subjective sense of feeling satiated. Journal of Experimental Psychology: General, 142(1), 209-217.

Richard, M., \& Chebat, J. (2016). Modeling online consumer behavior: Preeminence of emotions and moderating influences of need for cognition and optimal stimulation level. Journal of Business Research, 69, 541-553.

Seligman, M. E. P., \& Csikszentmihalyi, M. (2000). Positive psychology: An introduction. American Psychologist, 55, 5-14.

Solomon, R. L., \& Corbit, J. D. (1974). An opponent-process theory of motivation: Temporal dynamics of affect. Psychological Review, 81, 119-145.

Street \& Smith's SportsBusiness Daily. (2010, June 9). Fan demographics among major North American sports leagues. Retrieved from http://www.sportsbusinessdaily.com/Daily/Issues/2010/06/Issue-185/The-Back-Of-The$\underline{\text { Book/Fan-Demographics-Among-Major-North-American-Sports-Leagues.aspx }}$

Stroebe, M. S., \& Archer, J. (2013). Origins of modern ideas on love and loss: Contrasting forerunners of attachment theory. Review of General Psychology, 17(1), 28-39.

Tacikowski, P., Freiburghaus, T., \& Ehrsson, H. H. (2017). Goal-directed processing of selfrelevant information is associated with less cognitive interference than the processing of information about other people. Journal of Experimental Social Psychology, 68, 93-100. 
Taruffi, L., \& Koelsch, S. (2014). The paradox of music-evoked sadness: An online survey. PLoS ONE, 9(10), e110490.

Thayer, J. F., Ahs, F., Fredrikson, M., Sollers Iii, J. J., \& Wager, T. D. (2012). A meta-analysis of heart rate variability and neuroimaging studies: Implications for heart rate variability as a marker of stress and health. Neuroscience and Biobehavioral Reviews, 36, 747-756.

Trail, G. T., \& James, J. (2001). The motivation scale for sport consumption: A comparison of psychometric properties with other sport motivation scales. Journal of Sport Behavior, $24,108-127$.

Uhrich, S., \& Benkenstein, M. (2010). Sport stadium atmosphere: Formative and reflective indicators for operationalizing the construct. Journal of Sport Management, 24, 211-237.

Wann, D. L. (1995). Preliminary validation of the sport fan motivation scale. Journal of Sport and Social Issues, 19, 377-396.

Wann, D. L., \& Branscombe, N. (1990). Die-hard and fair-weather fans: Effects of identification on BIRGing and CORFing tendencies. Journal of Sport and Social Issues, 14, 103-117.

Westphal, M., Bonanno, G. A., \& Mancini, A. D. (2014). Attachment and attentional biases for facial expressions of disgust. Journal of Social and Clinical Psychology, 33, 169-186.

Wilson, E. O. (1978). On Human Nature. Cambridge: Harvard University Press.

Xing, C., \& Isaacowitz, D. M. (2006). Aiming at happiness: How motivation affects attention to and memory for emotional images. Motivation and Emotion, 30, 243-250.

Yoshida, M., Gordon, B., Nakazawa, M., \& Biscala, R. (2014). Conceptualization and measurement of fan engagement: Empirical evidence from a professional sport context. Journal of Sport Management, 28, 399-417. 
Table 1

Factor Correlations Matrix, Standardized Path Coefficients ( $\beta$ ), and Standard Errors (SE)

\begin{tabular}{|c|c|c|c|c|c|c|}
\hline Emotion & Factors & 1 & 2 & 3 & 4 & \\
\hline \multirow{4}{*}{ Negative } & iTeam ID & 1.00 & & & \multirow[b]{4}{*}{1.00} & \\
\hline & Flow & .16 & 1.00 & & & \\
\hline & Revisit & .20 & .22 & 1.00 & & \\
\hline & WOM & .16 & .31 & .62 & & \\
\hline \multirow{4}{*}{ Neutral } & iTeam ID & 1.00 & & & \multirow[b]{4}{*}{1.00} & \\
\hline & Flow & .22 & 1.00 & & & \\
\hline & Revisit & .44 & .57 & 1.00 & & \\
\hline & WOM & .29 & .48 & .78 & & \\
\hline \multirow{4}{*}{ Happiness } & iTeam ID & 1.00 & & & \multirow[b]{4}{*}{1.00} & \\
\hline & Flow & .07 & 1.00 & & & \\
\hline & Revisit & .06 & .37 & 1.00 & & \\
\hline & WOM & -.03 & .34 & .37 & & \\
\hline Emotion & \multicolumn{3}{|c|}{ Relationships } & $\beta$ & $\mathrm{SE}$ & $P$-value \\
\hline \multirow{6}{*}{ Negative } & \multicolumn{3}{|c|}{ iTeam ID $\rightarrow$ Flow } & $.16^{* *}$ & .21 & .001 \\
\hline & \multicolumn{3}{|c|}{ iTeam ID $\rightarrow$ Revisit } & $.17 * * *$ & .23 & $<.001$ \\
\hline & \multicolumn{3}{|c|}{ iTeam ID $\rightarrow$ WOM } & $.12 *$ & .23 & .02 \\
\hline & \multicolumn{3}{|c|}{ Flow $\rightarrow$ Revisit } & $.19 * * *$ & .05 & $<.001$ \\
\hline & \multicolumn{3}{|c|}{ Flow $\rightarrow$ WOM } & $.29 * * *$ & .06 & $<.001$ \\
\hline & \multicolumn{3}{|c|}{ Revisit \& WOM (correlations) } & $.59 * * *$ & .07 & $<.001$ \\
\hline \multirow{6}{*}{ Neutral } & \multicolumn{3}{|c|}{ iTeam ID $\rightarrow$ Flow } & $.22 *$ & .44 & .02 \\
\hline & \multicolumn{3}{|c|}{ iTeam ID $\rightarrow$ Revisit } & $.33 * * *$ & .36 & $<.001$ \\
\hline & \multicolumn{3}{|c|}{ iTeam ID $\rightarrow$ WOM } & $.19^{*}$ & .47 & .03 \\
\hline & \multicolumn{3}{|c|}{ Flow $\rightarrow$ Revisit } & $.50 * * *$ & .09 & $<.001$ \\
\hline & \multicolumn{3}{|c|}{ Flow $\rightarrow$ WOM } & $.44 * * *$ & .11 & $<.001$ \\
\hline & \multicolumn{3}{|c|}{ Revisit \& WOM (correlations) } & $69 * * *$ & .09 & $<.001$ \\
\hline \multirow{6}{*}{ Positive } & \multicolumn{3}{|c|}{ iTeam ID $\rightarrow$ Flow } & .07 & .27 & .53 \\
\hline & \multicolumn{3}{|c|}{ iTeam ID $\rightarrow$ Revisit } & .03 & .37 & .73 \\
\hline & \multicolumn{3}{|c|}{ iTeam ID $\rightarrow$ WOM } & -.06 & .26 & .58 \\
\hline & \multicolumn{3}{|c|}{ Flow $\rightarrow$ Revisit } & $.37 * *$ & .16 & .001 \\
\hline & \multicolumn{3}{|c|}{ Flow $\rightarrow$ WOM } & $.34 * *$ & .12 & .003 \\
\hline & \multicolumn{3}{|c|}{ Revisit \& WOM (correlations) } & $.28 *$ & .06 & .02 \\
\hline
\end{tabular}

$* P<.05 ; * * P<.01 ; * * * P<.001$. 


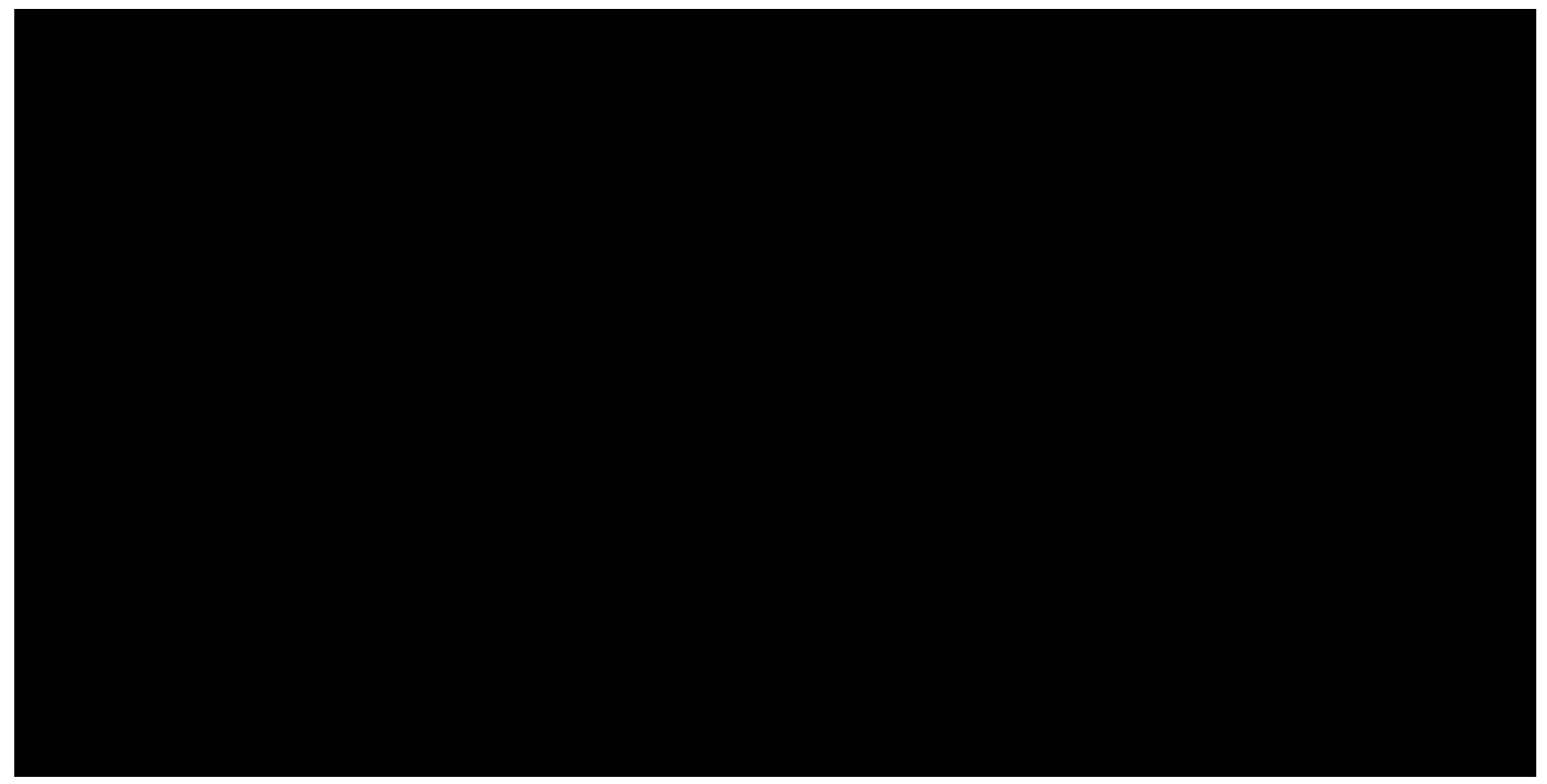

Figure 1. A hypothesized model 


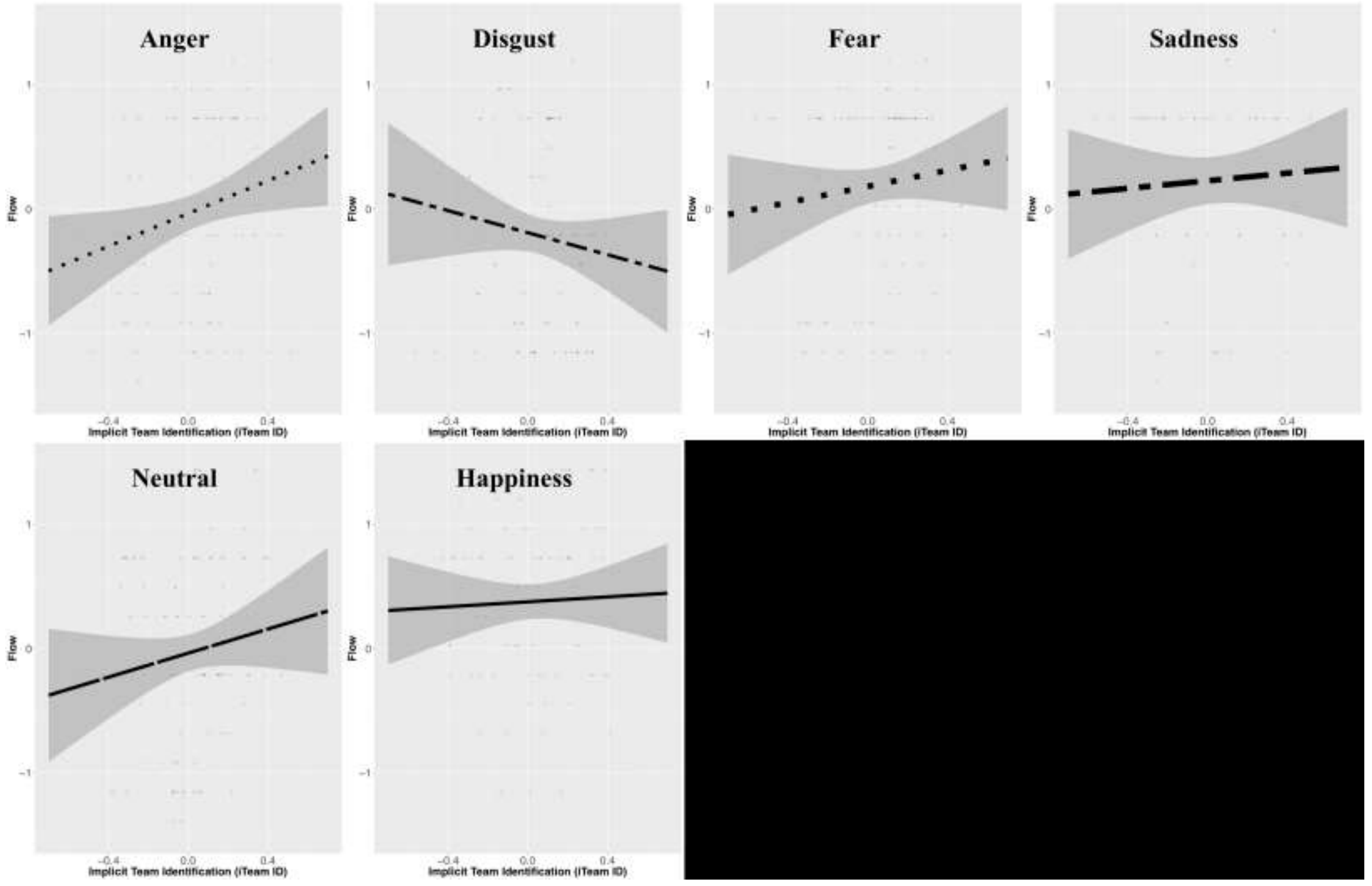

Figure 2. Results of the Interaction Effects of iTeam ID and Emotions on Flow 


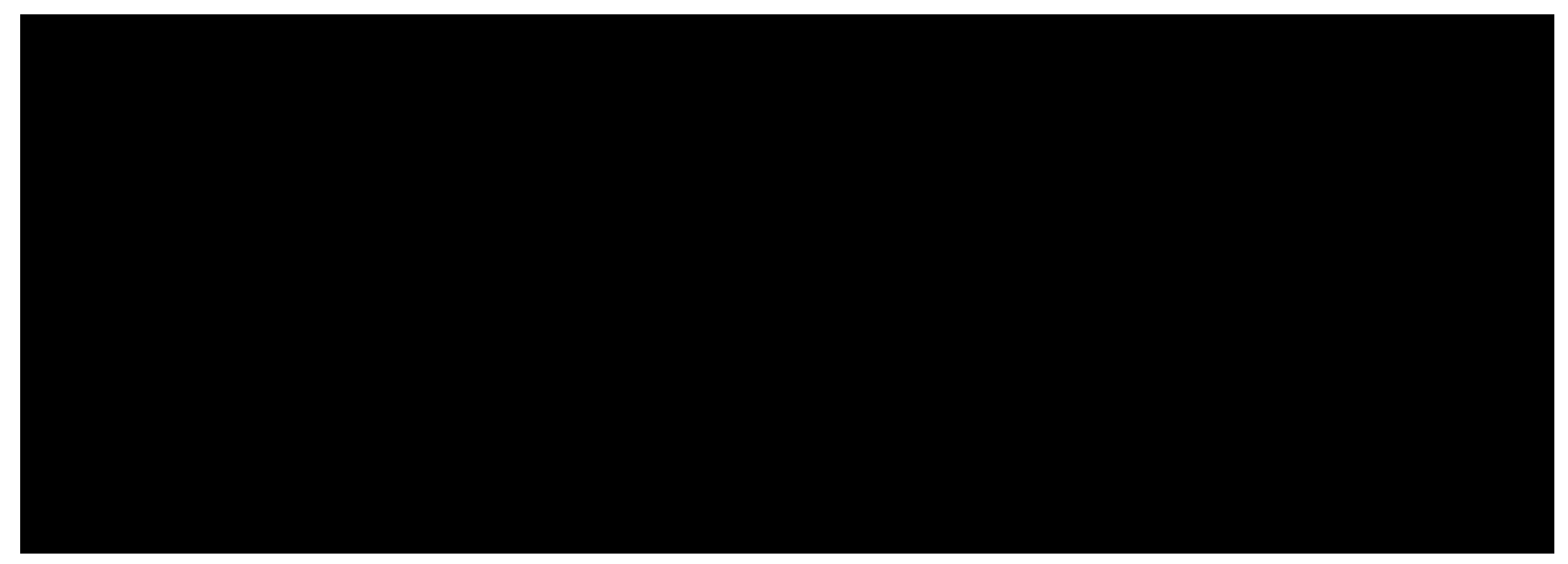

Note. Structural coefficients for Negative/Neutral/Positive emotions.

$* P<.05 ; * * P<.01 ; * * * P<.001$.

Figure 3. Results of the Moderated Mediation Effects 


\section{Appendix. Example Responses from the Writing Task of the Emotion Manipulation}

\begin{tabular}{|c|c|c|c|c|}
\hline Emotions & Opponents & Dates & Results & $\begin{array}{cc}\text { Response Samples } \\
\end{array}$ \\
\hline \multirow{2}{*}{ Anger } & Oklahoma & $10 / 22 / 2016$ & $\begin{array}{c}\mathrm{L}, \\
66-59\end{array}$ & $\begin{array}{l}\text { "the play that made me the most angry was when we let Joe Mixon score with 5:03 left in the fourth quarter. The reason this play made } \\
\text { me so angry was because this was Joe's 5th touchdown of the day against Texas Tech defense. We allowed him to rush for } 263 \text { yards } \\
\text { and } 2 \text { touchdowns while catching } 114 \text { years and } 3 \text { touchdown. This made me furious because we fought back all day and with just over } \\
5 \text { minutes left we couldn't hold them. We gave up that touchdown which put us down by } 14 \text { and basically gave OU the game." }\end{array}$ \\
\hline & TCU & $10 / 29 / 2016$ & $\begin{array}{c}\mathrm{W} \\
27-24\end{array}$ & $\begin{array}{l}\text { "The game was back and forth and very close. During the final play of the game Josh Doctson, the TCU quarterback, threw a pass into } \\
\text { the endzone that seemed to be incomplete, however, at the last second another player caught the ball that bounced off the hands of his } \\
\text { teammate and TCU won the game. The play looked hopeful at first and then turned out to be awful. I was furious." }\end{array}$ \\
\hline \multirow{2}{*}{ Disgust } & Oklahoma & $10 / 22 / 2016$ & $\begin{array}{c}\mathrm{L}, \\
66-59\end{array}$ & $\begin{array}{l}\text { "The play that made me sick was the touchdown by Dede Westbrook at the end of the half. We had previously just scored leaving very } \\
\text { little time on the clock to go into halftime. The second play of the Oklahoma drive was Westbrooks touchdown that was for } 65 \text { yards } \\
\text { and ended the half. This played made me sick to my stomach because we gave up the momentum going into half and the opportunity to } \\
\text { blow the game open when we came out from halftime. I was so sick that we allowed Oklahoma to score with no time at all." }\end{array}$ \\
\hline & $\begin{array}{l}\text { Arizona } \\
\text { State }\end{array}$ & $09 / 10 / 2016$ & $\begin{array}{c}\mathrm{L}, \\
55-68\end{array}$ & $\begin{array}{l}\text { "specific moment that made me feel sick was when our defense could not stop the other team's run offense. They had a running back } \\
\text { score } 6 \text { touchdowns against us and each time we knew what play was coming. i felt the sickest and literally wanted to throw up. Also I } \\
\text { do not like the smell of the tortillas that fans throw at the beginning of each game. It is not like a do not like that tradition, but the smell } \\
\text { of the tortillas lying in the floor makes me feel sick." }\end{array}$ \\
\hline \multirow[b]{2}{*}{ Fear } & $\begin{array}{l}\text { Arizona } \\
\text { State }\end{array}$ & $09 / 10 / 2016$ & $\begin{array}{c}\mathrm{L}, \\
55-68\end{array}$ & $\begin{array}{l}\text { "I was anxious during the } 4 \text { th quarter of the game because Tech needed a touchdown to tie, and time was running out. I was fearful } \\
\text { that the shootout of the game was slipping away. I felt anxiety with less than 2:00 minutes to play, when Tech finally was able to tie the } \\
\text { game up. My anxiety continued throughout both overtime sessions. The anxiousness lasted all the way to the end." }\end{array}$ \\
\hline & TCU & $10 / 29 / 2016$ & $\begin{array}{c}\mathrm{W}, \\
27-24\end{array}$ & $\begin{array}{l}\text { "The field goal to win the game in double overtime is the play that made me the most anxious. As the ball was kicked, I could tell it was } \\
\text { not a good kick, which heightened my anxiety and made me fearful that is was not going to be good. The end result was that the field } \\
\text { goal was good, but prior to the kick and as the ball was in the air my anxiety was very high and grew stronger until the ball went } \\
\text { through the upright." }\end{array}$ \\
\hline \multirow[t]{2}{*}{ Sadness } & $\begin{array}{c}\text { West } \\
\text { Virginia }\end{array}$ & $10 / 15 / 2016$ & $\begin{array}{c}\mathrm{L}, \\
48-17\end{array}$ & $\begin{array}{l}\text { "the play that made me feel depressed, sad and helpless was the bad snap by our deep snapper in the third quarter. We lined up to punt } \\
\text { the ball, already down by } 14-21 \text { points to which we had a bad snap and gave the ball to West Virginia deep in their territory of the } \\
\text { field. They scored shortly after this play eliminating any chance for us to possibly win the game. The bad snap made me feel completely } \\
\text { helpless because we seemed to do nothing right the whole game and that was the icing on top of the cake for us. The game resulted in a } \\
\text { huge blowout loss for us during homecoming. I felt much depressed and helplessness." }\end{array}$ \\
\hline & Kansas & $09 / 29 / 2016$ & $\begin{array}{c}\mathrm{W}, \\
19-55\end{array}$ & $\begin{array}{l}\text { "I was sad when Patrick Maholmes got hurt during the game. He was flipped by the opposing player and it looked horrible! I was so } \\
\text { sad because he was slow to get up and I was helpless that the season was basically over. I felt helpless due to the fact that noone could } \\
\text { really do anything about it except for pray. That was a scary day for Tech football I had felt depressed and sad for three days after that. } \\
\text { It was the worst I've ever felt because of a football game." }\end{array}$ \\
\hline \multirow{2}{*}{ Happiness } & Oklahoma & $10 / 22 / 2016$ & $\begin{array}{c}\mathrm{L}, \\
66-59\end{array}$ & $\begin{array}{l}\text { "I remember the game where it was the first time Baker Mayfield came back but on opposite teams. I loved how energized and happy } \\
\text { everyone was just to watch this game. Baker Mayfield got boo'd and the intensity of the game was extremely high. We did not win the } \\
\text { game but I left feeling really satisfied with the way we played. We weren't the winner, but we did far better than I expected which made } \\
\text { the game very enjoyable." }\end{array}$ \\
\hline & Texas & $11 / 05 / 2016$ & $\begin{array}{c}\mathrm{L}, \\
45-37\end{array}$ & $\begin{array}{l}\text { "most enjoyable memory of the season was when the tech defensive player ripped the football out of the Longhorns Running back. He } \\
\text { fumbled the ball on the Tech one yard line and returned it for a touchdown. This happened right before halftime which made the game } \\
\text { close going into half time. I think the reason this play was so enjoyable was because the UT player was inches away from falling in for } \\
\text { a touchdown. It really changed the momentum of the game and put in back in the game before half time." }\end{array}$ \\
\hline
\end{tabular}

